\title{
Clinico-Etiological Profile of Neonatal Seizures in Term Neonates: A Study in a Tertiary Care Hospital, Dhaka, Bangladesh
}

\author{
Mohammad Moniruzzaman Bhuiyan ${ }^{1 *}$, Nadira Dilruba Hoque ${ }^{2}$, Mahfuza Nasrin $^{3}$, Md. Ibrahim Khalil $^{4}$, Nasrin Akhter $^{5}$
}

${ }^{1}$ Assistant Professor, Department of Pediatrics, Sir Salimullah Medical College (SSMC) \& Mitford Hospital, Dhaka, Bangladesh

${ }^{2}$ Assistant Professor, Department of Pediatrics, Sir Salimullah Medical College (SSMC) \& Mitford Hospital, Dhaka, Bangladesh

${ }^{3}$ Associate Professor, Department of Microbiology, Uttara Adhunik Medical College, Dhaka, Bangladesh

${ }^{4}$ Assistant Professor, Department of Pediatrics, Sir Salimullah Medical College (SSMC) \& Mitford Hospital, Dhaka, Bangladesh

${ }^{5}$ Assistant Professor (Psychiatry), Mugda Medical College, Dhaka, Bangladesh

DOI: $10.36347 /$ sjams.2020.v08i09.041

| Received: 09.09.2020 | Accepted: 25.09.2020 | Published: 30.09.2020

*Corresponding author: Mohammad Moniruzzaman Bhuiyan

Abstract

Original Research Article

Background: Neonatal seizures or neonatal convulsions are epileptic fits occurring from birth to the end of the neonatal period. Neonatal seizures are a common neurological problem with a frequency of 1.5-14/1000 neonates. Neonatal seizure is common in this part of the South Asia and there was paucity of data from this area. Objective: Identification of etiology will help in management there by reducing morbidity and mortality. Materials and Methods: This prospective study was done in NICU Pediatrics Dept. of Tertiary Care Hospital, Dhaka, Bangladesh from Jan 2018 to Jan 2019. Term neonates with clinically identifiable seizure were included in the present study. Preterm neonates, babies with neonatal tetanus, and babies with obvious congenital malformation were excluded. Results: Out of 84 studied neonates, 46 were males and 38 were females. 29 neonates had seizures within first 24 hours and 22 neonates had seizures on day 2. Perinatal asphyxia was seen in 28 neonates and septicemia was seen in 21 neonates. Conclusion: Perinatal asphyxia was the most common cause for neonatal seizures in term neonates, followed by septicemia and metabolic disturbances.

Keywords: Neonatal Seizures, Perinatal Asphyxia, Septicaemia.

Copyright @ 2020: This is an open-access article distributed under the terms of the Creative Commons Attribution license which permits unrestricted use, distribution, and reproduction in any medium for non-commercial use (NonCommercial, or CC-BY-NC) provided the original author and source are credited.

\section{INTRODUCTION}

Neonatal seizures or neonatal convulsions are epileptic fits occurring from birth to the end of the neonatal period [1]. Neonatal seizures are a common neurological problem with a frequency of 1.5-14/ 1000 neonates. The seizures in neonates may manifest as paroxysmal alteration in motor, sensory, behavioral or autonomic dysfunctions [2]. Clinically, there are four seizure types: subtle, clonic, tonic, and myoclonic. Each one can be focal, multifocal, and generalized [3]. Etiologically, about $80-85 \%$ of neonatal seizures are symptomatic and rest are idiopathic. The most common cause is hypoxic ischemic encephalopathy (HIE); the other causes include hemorrhage, metabolic disturbances, and infections [4]. Seizures are often the first sign of neurological dysfunction in newborns [5]. Infants with neonatal seizures are at increased risk of morbidity and mortality. The babies who survive may have adverse effects on motor, cognitive, and behavioral development or epileptic complications in the later part of the life [6]. The present study was conducted to determine the etiological factors for neonatal seizures in our hospital. The result of the study will help in planning management of neonatal seizure to improve the short term as well as long term outcome.

\section{Materials And Methods}

This prospective study was done in NICU Pediatrics Dept. of Tertiary Care Hospital, Dhaka, Bangladesh from Jan 2018 to Jan 2019. All the term neonates with clinically identifiable seizures before 28 days of life were enrolled in the study. Preterm neonates, babies with neonatal tetanus, and babies with obvious congenital malformation were excluded. A detailed antenatal, natal, postnatal, and family history was obtained and documented in predesigned proforma. Diagnosis of HIE was based on history, physical examination, Apgar score, arterial blood gas, MRI of brain or cranial sonography. Diagnosis of neonatal infection was based on clinical manifestations, sepsis screening tests and blood culture, CSF analysis. Metabolic disorders were considered as hypoglycemia (serum glucose $<40 \mathrm{mg} / \mathrm{dl}$ ), hypocalcaemia (Total serum $\mathrm{Ca}<8 \mathrm{mg} / \mathrm{dl}$ in full term.), and hypomagnesaemia 
(serum magnesium levels $<1.5 \mathrm{mg} / \mathrm{Dl}$ ). Intracranial hemorrhages were diagnosed by CT scan brain. The results were analyzed by appropriate statistical methods.

\section{RESULTS}

In the present study, 84 neonates with chief complaints of seizures were included. $46(55 \%)$ were males and $38(45 \%)$ were females (Table-1). 53 $(63.1 \%)$ neonates were between 37 to 39 weeks of gestation, while 31 (36.9\%) neonates were between 40 to 41 weeks of gestation. 44 neonates had vaginal delivery and 40 neonates were delivered by cesarean section. Onset of seizure was day 1 in $29(34.5 \%)$, day 2 in $22(26.2 \%)$, and day 3 of life in $8(9.5 \%)$ neonates (Table-2). The most common type of seizure seen was focal clonic type $(n=28,33.3 \%)$; followed by subtle seizures $(\mathrm{n}=26,31 \%)$, myoclonic $(\mathrm{n}=15,17.9 \%)$, focal tonic $(\mathrm{n}=7,8.3 \%)$, multifocal $(\mathrm{n}=, 6 \%)$, and generalized tonic clonic type $(n=3,3.6 \%)$ (Table-3). Among the studied population, perinatal asphyxia was identified as the most common cause of neonatal seizure $(n=28$, $33.3 \%)$. This was followed closely by septicemia $(n=21$, $25.0 \%$ ). Other significant causes identified were hypocalcemia $(n=10,11.9 \%)$, hypoglycemia $(n=8$, $9.5 \%)$, hyperbilirubinemia $(\mathrm{n}=5,6 \%)$, intracranial hemorrhage $(n=4,4.7 \%)$ brain malformations $(n=4$, $4.7 \%$. While, $3(3.5 \%)$ neonates had hypomagnesaemia and $1(1.2 \%)$ neonate had seizures due to lignocaine injection (Table-4).

Table-1: Sex wise distribution of cases $(\mathrm{N}=84)$

\begin{tabular}{|l|l|l|}
\hline Sex & Total & \% \\
\hline Male & 46 & $54 \%$ \\
\hline Female & 38 & $46 \%$ \\
\hline Total & 84 & 100 \\
\hline
\end{tabular}

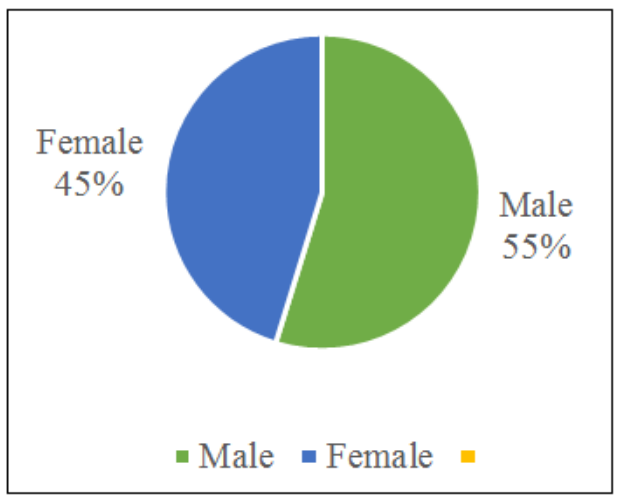

Fig-1: Sex wise distribution of cases $(\mathrm{N}=\mathbf{8 4})$

Table-2: Distribution of cases according to onset of seizures $(\mathrm{N}=84)$

\begin{tabular}{|l|l|l|}
\hline Day of onset & Number of patients & \% \\
\hline 1 & 29 & 34.5 \\
\hline 2 & 22 & 26.2 \\
\hline 3 & 8 & 9.5 \\
\hline 4 & 5 & 6 \\
\hline 5 & 2 & 2.4 \\
\hline 6 & 4 & 4.8 \\
\hline 7 & 4 & 4.8 \\
\hline$>8$ & 10 & 11.9 \\
\hline Total & 84 & 100 \\
\hline
\end{tabular}

Table-3: Distribution of seizures according to type of seizures $(\mathrm{N}=84)$

\begin{tabular}{|l|l|l|}
\hline Type of seizure & Number of patients & \% \\
\hline Focal clonic & 28 & 33.3 \\
\hline Subtle & 26 & 31 \\
\hline Myoclonic & 15 & 17.9 \\
\hline Focal tonic & 07 & 8.3 \\
\hline GTCS & 03 & 3.6 \\
\hline Multi focal & 05 & 6 \\
\hline Total & 84 & 100 \\
\hline
\end{tabular}

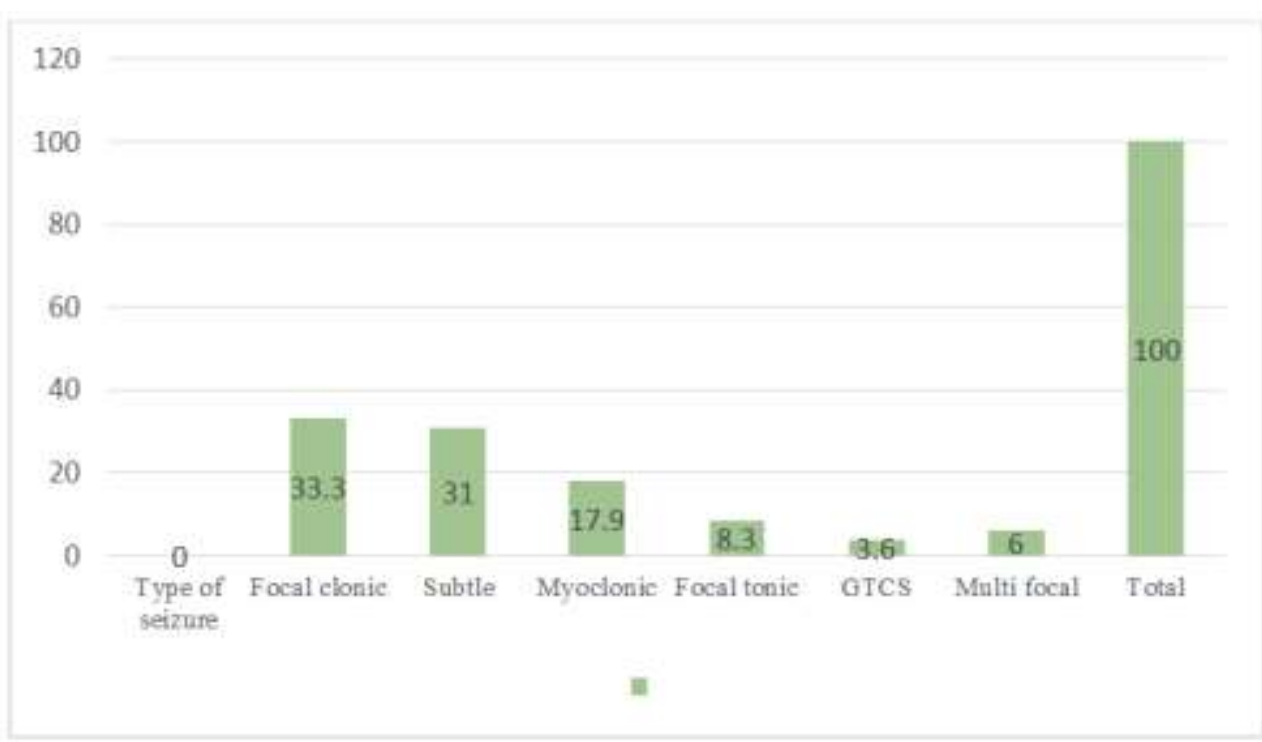

Fig-2: Distribution of seizures according to type of seizures $(\mathrm{N}=\mathbf{8 4})$ 
Table-4: Distribution of seizures according to aetiology $(\mathrm{N}=84)$

\begin{tabular}{|l|l|l|}
\hline Aetiology of seizures & Number of patients & \% \\
\hline HIE & 28 & 33.3 \\
\hline Sepsis & 21 & 25 \\
\hline Hypocalcaemia & 10 & 11.9 \\
\hline Hypoglycaemia & 8 & 9.5 \\
\hline Hypomagnesemia & 3 & 3.5 \\
\hline Intracranial haemorrhage & 4 & 4.7 \\
\hline Hyperbilirubinemia kernicterus & 5 & 5.9 \\
\hline Brain malformation & 4 & 4.7 \\
\hline Drug withdrawal & 1 & 1.2 \\
\hline Total & 84 & 100 \\
\hline
\end{tabular}

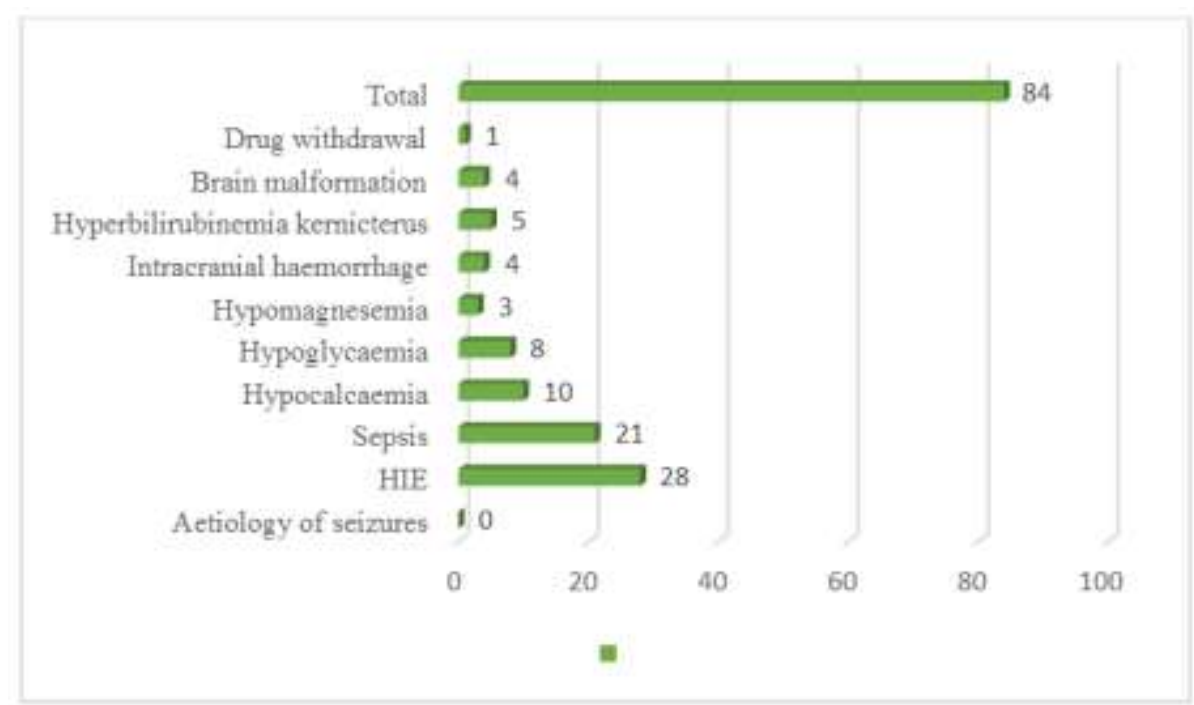

Fig-3: Distribution of seizures according to aetiology $(\mathrm{N}=\mathbf{8 4})$

\section{DISCUSSION}

Neonatal seizures are a common neurological problem with a frequency of 1.5-14/1000 neonates. Etiologically, about $80-85 \%$ of neonatal seizures are symptomatic and rest are idiopathic. The most common cause is hypoxic ischemic encephalopathy (HIE); the other causes include hemorrhage, metabolic disturbances, and infections [4]. In our present study, 46 $(54.76 \%)$ neonates were male and $38(45.23 \%)$ were females with slight male predominance 1.2:1 (Table-6 and Graph-2) Table-1. This finding was similar to the studies done by the Sahana G et al., [7], Sabzehei MK et al., [3], Parvin R et al., [8], and Moayedi AR et al., [9]. $44(52 \%)$ babies with neonatal seizure were born through the vaginal delivery and $40(47 \%)$ babies were through the LSCS. This was found similar with the study done by Sabzehei MK et al., [3] (53\% and 47\% respectively). Of the 84 neonates with seizures, 29 (34.5\%) had seizures on day 1 followed by $22(26.2 \%)$ on day 2 of life, $8(9.5 \%)$ on day 3 , and $10(11.9 \%)$ on day $>=8$ days of life. A total of $59(50.3 \%)$ neonates had seizures within first 3 days of life (Table-2). Similar findings was found by the Sahana $G$ et al., [7] and Ronen Gabriel et al [10]. Based on clinical seizure types, $28(33.3 \%)$ neonates had focal clonic type followed immediately by the subtle seizures in 26 (31.0\%). Myoclonic type of seizures was seen in 15
(17.9\%), focal tonic type in $7(8.3 \%)$ and multifocal type in $5(6.0 \%)$ neonates. This was found in concordance with the study done by Aziz A et al., [11] and Verma YS et al., [12]. Table-3 perinatal asphyxia was the most common cause of neonatal seizures identified in $33.3 \%$ of neonates. This was found to be in concordance with the study done by Najeeb $\mathrm{S}$ et al., [13], (46\%). Sabzehei MK et al., [3], (34\%), Glass HC et al., [14] (38\%) and Malik BA et al., [15], (35\%). In other studies, done by Verma YS et al., [12] (70\%) of neonates had seizures due to hypoxic ischemic encephalopathy. In the present study 21 (25\%) of 84 babies had sepsis (septicemia and meningitis). This was found similar to the study done by Parvin R et al., [8], (26\%, n=51), Sabzehei MK et al., [3], $(24.4 \% \mathrm{n}=102)$ and was found to be (29\%) by the study done by Najeeb S et al., [13]. In another study done by Malik BA et al., [15], 34\% of babies had septicemia. In the present study $1(4.8 \%)$ baby had herpes infection as the cause for seizure which was found similar to the study done by Parvin R et al., [8], (1.96\%). Seizures due to hypoglycemia in association with comorbidities like HIE, Septicemia and IDM were accounted for 37 (44\%) whereas $8(9.5 \%)$ babies had seizure only due to hypoglycemia without any comorbidities. This was seen in concordance with the study done by Kumar A et al., [5], (11.11\%), Sahana G et al., [7] (9.17\%). This is 
probably because of depletion of glycogen storage and inadequate feeding during early postnatal days. Seizures due to hypocalcemia associated with other comorbidities like perinatal asphyxia, septicemia and IDM were $19(22.6 \%)$ babies, whereas isolated hypocalcemia causing seizures were found in 10 $(11.9 \%)$ of the 84 neonates studied. This was found similar to the study done by Parvin $\mathrm{R}$ et al., $815.65 \%$ $(\mathrm{n}=51)$ and Taksande A M et al., [16] $(\mathrm{n}=110)$ where they found to be $11.8 \%$ and Verma YS et al., [12] found it to be $11.67 \%(n=60)$. In $3(3.5 \%)$ cases neonatal seizure was caused by hypomagnesemia. Similar finding was seen by Taksande A. M et al., [16]. Seizures due to hyperbilirubinemia (kernicterus) was seen in $5(6 \%)$ neonates in the present study. Similar findings were found in study done by Najeeb $\mathrm{S}$ et al., [13], $(n=6,6 \%) .4(4.7 \%)$ neonates had seizures due to intracranial hemorrhage. Similar findings were seen by Najeeb $\mathrm{S}$ etal13 $(\mathrm{n}=100,4 \%)$ and SudiaS et al., [17], $(n=90,4.6 \%)$. Seizures due to lignocaine toxicity was seen in $1(1.2 \%)$ neonate in our study, similar finding was seen by Malik BA et al., [15], Malik BA et al., [15], $(\mathrm{n}=2,1 \%)$.

\section{CONCLUSiON}

The present study shows perinatal asphyxia is the most common cause of neonatal seizures among term neonates in our setup. The other causes followed in order are septicemia, metabolic (hypoglycemia, hypocalcemia, hypomagnesemia and hyperbilirubinemia), intracranial hemorrhages and brain malformations. Early identification of at risk pregnancies, institutional delivery and aseptic precautions with timely resuscitation is recommended to reduce morbidity and mortality due to neonatal seizures.

\section{REFERENCES}

1. Panayiotopoulos CP. The Epilepsies: Seizures, Syndromes and Management. Oxfordshire (UK): Bladon Medical Publishing; 2005. Chapter 5, Neonatal Seizures and Neonatal Syndromes. Available from: https:// www.ncbi.nlm.nih.gov/books/NBK2599/

2. Das D, Debbarma S. A Study on ClinicoBiochemical Profile of Neonatal Seizure. Journal of Neurology Research, North America, 6, dec. 2016. Available at: <http:// www.neurores.org/index.php/neurores/article/ view/404/399>. Date accessed: 20 May. 2017.

3. Sabzehei MK, Basiri B, Bazmamoun H. The Etiology, Clinical Type, and Short Outcome of Seizures in Newborns Hospitalized in Besat Hospital/Hamadan/ Iran. Iran J Child Neurol. 2014 spring; 8(2):24-8.

4. Kang SK, Kadam SD. Neonatal Seizures: Impact on Neurodevelopmental Outcomes. Front Pediatr. 2015 Nov 23; 3: 101.
5. Kumar A, Gupta A, Talukdar B. Clinicoetiological and EEG profile of neonatal seizures. Indian J Pediatr. 2007 Jan; 74(1):33-7.

6. M Levene. The clinical conundrum of neonatal seizures. Arch Dis Child Fetal Neonatal Ed. Mar 2002; 86(2): F75-F77.

7. Sahana G, Anjaiah B. Clinical profile of neonatal seizures. International journal of medical and applied sciences. Jan-March. 2014, 3(1):21-27.

8. Parvin R, Afmsalim, Rahman M, Chowdhury K, Sultana A, Ahmed S, et al. Neonatal Seizures: Correlation between Clinico-Etiological Profile and EEG Findings. Bangladesh J Child Health 2014; Vol 38 (1):

9. Moayedi AR, Zakeri S; Moayedi F. Neonatal seizure: etiology and type. Iranian Journal of Child Neurology, [S.1.], Nov. 2008; 2(2):23-26. ISSN 2008-0700. Available at: <http:// journals.sbmu.ac.ir/index.php/ ijcn/article/ view/458>. Date accessed: 17 Dec. 2014.

10. Ronen GM, Rosales TO, Connolly M, Anderson VE, Leppert $M$. Seizure characteristics in chromosome 20 benign familial neonatal convulsions. Neurology. 1993 Jul; 43(7):1355-60.

11. Aziz A, Gattoo I, Aziz M, Rasool G. Clinical and etiological profile of neonatal seizures: a tertiary care hospital based study. Int J Res Med Sci. 2015; 3:2198-2203.

12. Verma YS, Dutt R, Rajput N, Patil R. Predictive value of EEG for neuro-developmental outcome in neonatal seizures. Journal of Evolution of Medical and Dental Sciences 2013; 2(29):5417-5425.

13. Najeeb S, Qureshi AM, Ahmad F, Shah S, Khan AY, Siddiqui TS. Aetiology and types of neonatal seizures presenting at Ayub Teaching Hospital Abbottabad. Journal of Ayub Medical College Abbottabad. 2012 Mar 1;24(1):33-7.

14. Glass HC, Shellhaas RA, Wusthoff CJ, Chang T, Abend NS, Chu CJ, Cilio MR, Glidden DV, Bonifacio SL, Massey S, Tsuchida TN. Contemporary profile of seizures in neonates: a prospective cohort study. The Journal of pediatrics. 2016 Jul 1;174:98-103.

15. Malik BA, Butt MA, Shamoon M, Tehseen Z, Fatima A, Hashmat N. Seizures etiology in the newborn period. J Coll Physicians Surg Pak. 2005 Dec; 15(12):786-90.

16. Taksande AM, Krishna V, Manish Jain, Mahaveer L. Clinico-biochemical profile of neonatal seizures. PaedOncall Journal. 2005 October; 2(10). Available from: http:// www.pediatriconcall.com/Journal/

17. Sudia S, Berwal PK, Nagaraj N, Jeavaji P, Swami $\mathrm{S}$, Berwal A. Clinicoetiologicalprofile and outcome of neonatal seizures. Int J Contemp Pediatr. 2015; 2:389-90. 